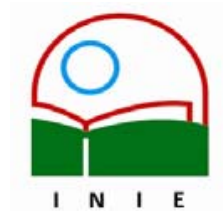

Actualidades Investigativas en Educación

Revista Electrónica publicada por el

Instituto de Investigación en Educación

Universidad de Costa Rica

ISSN 1409-4703

http://revista.inie.ucr.ac.cr

COSTA RICA

\title{
LEER POR PLACER EN LOS COLEGIOS: ¿MISIÓN IMPOSIBLE?
}

READ FOR PLEASURE IN SCHOOLS: MISSION IMPOSSIBLE?

Volumen 8, Número 3

pp. 1-26

Este número se publicó el 15 de diciembre 2008

Isabel Gallardo Álvarez

La revista está indexada en los directorios:

LATINDEX, REDALYC, IRESIE, CLASE, DIALNET, DOAJ, E-REVIST@S,

La revista está incluida en los sitios:

REDIE, RINACE, OEI, MAESTROTECA, HUASCARAN

Los contenidos de este artículo están baj o una licencia Creative Commons 


\title{
LEER POR PLACER EN LOS COLEGIOS: ¿MISIÓN IMPOSIBLE? READ FOR PLEASURE IN SCHOOLS: MISSION IMPOSSIBLE?
}

\section{Isabel Gallardo Álvarez ${ }^{1}$}

\begin{abstract}
Resumen: El presente artículo es fruto del trabajo en el aula universistaria, donde junto con los grupos de estudiantes, se buscaron formas alternativas de atraer a los estudiantes de secudaria a la lectura. En él se reflexiona sobre las causas por las cuales el grupo de jóvenes que asiste a los colegios de secundaria se resiste a leer. Para ello se indaga tanto en las razones sociales y tecnológicas, como las educativas y se buscan explicaciones a la negativa de enfrentarse a un texto literario. Además, se revisan los contenidos sobre la lectura de textos literarios que propone el Ministerio de Educación Pública Costarricense, así como las novelas de lectura obligatoria. Finalmente, se presentan dos actividades basadas en la imagen, que buscan despertar el gusto por la lectura y acercar al joven a desarrollar esta habilidad.
\end{abstract}

Palabras clave: LECTURA, TEXTOS LITERARIOS, COMPETENCIA LECTORA, HABILIDAD DE LEER, ACTIVIDADES CREATIVAS

Abstract: This article is the result of work in the high education classroom, which along with student groups, were sought alternative ways to attract students secudaria to reading. It reflects on the reasons why the group of young people who attend secondary schools are reluctant to read. This explores both the technological and social reasons, such as educational and sought explanations for the failure to address a literary text. In addition, we review the content on the reading of literary texts proposed by the Costarrican Ministry of Public Education, as well as the novels of required reading. Finally, there are two activities based on the image, seeking to awaken the taste for reading and bring the youth to develop this skill.

Key words: READING, LITERARY TEXTS, READING COMPETITION, READING ABILITY, CREATIVE ACTIVITIES

\section{Introducción}

No es un secreto para nadie que la cultura de la lectura se encuentra en desuso; por ello, es común oír a docentes de Español quejarse porque sus estudiantes no leen los textos literarios asignados en clase. Esta queja ha llevado a algunos estudiosos del tema a sugerir que el acercamiento al texto literario se aborde desde una nueva perspectiva, buscando experiencias que superen la sola lectura del texto y el análisis estructural que comúnmente se hace (Ramírez, 2006). Mauricio Ostria, profesor de literatura chileno, apoya estas ideas, al enunciar:

\footnotetext{
${ }^{1}$ Licenciada en Filología Española, Bachillerato en la Enseñanza del Castellano y la Literatura ambos de la Universidad de Costa Rica. Profesora de la Escuela de Formación Docente. Investigadora del Instituto de Investigación en Educación (INIE). Directora y asesora de diferentes Trabajos Finales de Graduación.
}

Correo electrónico: isabella gallardo@hotmail.com

Artículo recibido: 3 de setiembre, 2008

Aprobado: 4 de diciembre, 2008 
Se ha hecho un lugar común el afirmar que cada vez se lee menos y que en los ámbitos estudiantiles no existe el debido interés por la lectura, especialmente referida a obras literarias. Se suele vincular el problema a la presencia invasiva de medios audiovisuales, tecnologías computacionales, juegos electrónicos, etc. (Ostria, 2005, p.2)

No se lee por muchas razones, Ostria apunta la presencia invasiva de la tecnologías digitales y de entretenimiento, pero hay otras que expondré en este artículo.

Otra razón que incide en la falta de hábitos lectores, se encuentra en los textos literarios que se leen en el aula y la manera como el grupo de docentes de Español lo presenta en el aula; se guía al estudiante a un acercamiento que pareciera buscar que este incipiente lector se convierta en un experto analista literario, capaz de desentrañar la estructura del texto y su significado implícito. Para promover esta lectura de los textos literarios el sistema educativo costarricense propone un acercamiento estructuralista formal, unido a algunos conceptos extraídos de la sociocrítica; pero este tipo de lectura no acerca al grupo de jóvenes a la lectura, más bien los aleja cada vez más, por ello es necesario indagar otras formas de acercamiento a la lectura, que impliquen el aspecto lúdico y creativo con la finalidad de enamorar al estudiante en la lectura

Una razón más, unida a la anterior, se encuentra en la lista limitada de textos literarios que se deben leer obligatoriamente en el Tercer Ciclo de la Educación General Básica y Diversificada, libros que además hay que analizar con las herramientas teóricas antes comentadas y que serán objeto de evaluación en distintas pruebas a lo largo del año. Esa es la motivación que tiene el joven para leer esos textos, conocer su estructura y contenido, para responder pruebas, cuestionarios y tareas que le asigna su docente.

Dice Daniel Penac en su libro Como una novela (1999) que la lectura, como el amor, no admite el modo imperativo, no se puede obligar a leer como no se puede obligar a amar o a soñar. Además, si se toma en cuenta la etapa de desarrollo en que se encuentran estos lectores obligados: la adolescencia, donde leer por obligación para cumplir con un programa de estudio no lo atrapa ni hace que disfrute el placer del texto.

Para que el alumnado le tome placer al acto de la lectura son necesarios cambios en el acercamiento a este tema, cambios tanto en los programas oficiales para la enseñanza de la literatura, como en la actitud del docente al enfrentarse al texto literario. Este último tiene que cambiar la manera de enseñar literatura, adaptarse a las nuevas épocas y buscar, no que el Volumen 8, Número 3, Año 2008, ISSN 1409-4703 
grupo estudiantil se convierta en un experto crítico literario, sino en promover la competencia comunicativa, en la que el acto de leer permita no solo comprender el texto, interpretarlo y disfrutarlo, sino también desarrollar las habilidades comunicativas para desenvolverse en el mundo: leer, escribir, escuchar y hablar.

Para lograr estos objetivos, este artículo propone formas de acercamiento al texto, dirigidas a leer desde el placer y la creatividad, usando técnicas agradables cercanas al juego y la creatividad y que lo lleven a un reencuentro con la literatura como hecho comunicativo, de placer y conocimiento. Este es el objetivo central que persigue la escritura de este artículo.

Antes de proponer estas formas para abordar el texto, es necesario responderse a la pregunta porqué los jóvenes que cursan la educación secundaria, se resisten a la lectura de textos literarios. Este será un objetivo secundario que también buscará responderse en las líneas que se leerán a continuación.

\section{¿Porqué los adolescentes no leen? Reflexiones teóricas en torno al problema}

De acuerdo con algunos teóricos que hablan sobre el porqué el grupo de jóvenes no lee (Ostria, 2005; Martín Barbero, 1993; Méndez Anchía, 2002 y 2007, Gallardo, 2006) es posible resumir la respuesta en tres razones: falta de cultura lectora en el hogar, el desconocimiento de la forma de descifrar el código escrito por su educación audiovisual y, en tercer lugar, textos de lectura obligatoria en el colegio y un acercamiento por parte del docente poco motivadores para la edad y conocimientos.

Desarrollaré en forma breve estas tres razones, pues el tema que ocupa en este artículo se centra en indagar la manera de acercar al adolescente a la literatura y no en recordar las razones por las que la lectura se ha vuelto una práctica en desuso. ${ }^{2}$

En primer lugar, me referiré a la falta de cultura lectora en el hogar. Actualmente los niños y niñas, en sus primeros años, son arrullados por la televisión o el sonido de los juegos de vídeo que usan los otros miembros de la familia. La lectura de cuentos antes de dormir es una práctica olvidada, así como la compra o regalo de libros de cuentos. En las casas de

2 Estas razones se encuentran investigadas y comentadas a profundidad en el artículo de esta autora del año 2006. La lectura en los colegios ¿porqué no leen los jóvenes? En: Revista Educación. Universidad de Costa Rica. Vol. 30(1) 
estos infantes no existe una biblioteca, no se leen los periódicos y los mismos progenitores no tienen el hábito de la lectura. Dice Fernando Alonso, escritor español:

El lector de obras literarias nace en la infancia. En la primera infancia. El lenguaje oral, y el lenguaje escrito, son extensiones del hombre, que facilitan y posibilitan su comunicación y, con ello, su condición de «ser social». Por consiguiente, el acceso al libro debe ser simultáneo, en tiempo y forma, al acceso al lenguaje oral.

El niño nace como lector siguiendo pautas de mimetismo, cuando trata de imitar a los adultos que leen en su presencia. Así, desde su primera infancia, contemplará el libro como un bien cotidiano y necesario. (Alonso, 2007b, p. 1)

Por lo tanto, si al nacer y crecer en el hogar no hay libros, ni sus padres leen, es difícil aprender el hábito de la lectura e identificarse con esta cultura, ya que como dice Alonso, los progenitores son el primer ejemplo para que el infante aprenda un hábito. Y luego en la escuela, se lee poco y con el objetivo inicial que el grupo infantil aprenda a descifrar el código escrito y más adelante a realizar tareas específicas, dirigidas por la maestra o maestro, con la literatura que se lee en el aula.

En segundo lugar, se encuentra la dificultad que se les presenta a los adolescentes para descifrar el código escrito e impreso de un libro. La causa tiene su anclaje en su educación audiovisual, producto de la globalización, el auge de los multimedia y de la aparición de nuevas formas tecnológicas de diversión. La llegada de la Internet, el uso masificado de los teléfonos celulares, la comunicación virtual mediante el chat, entro otros, hacen al joven, nativos digitales (Cassany, 2008), relacionados íntimamente con esta cultura que los aleja de la letra impresa, la lectura en solitario y la diversión mediante un libro. Dice Mauricio Ostria, de la Universidad de Concepción (Chile):

Frente a una cultura en que las fuentes de información, las formas de conocimiento y los medios de lectura se multiplican y en que, consiguientemente, el libro deja de ser el centro, el lugar privilegiado del conocimiento, las políticas de fomento del libro y la lectura, especialmente a través de los medios de enseñanza, debieran ser especialmente permeables a todo tipo de estrategias tendientes al aprovechamiento de esas otras fuentes, formas y lecturas multimediales con las que el libro compite. Quizá la actual crisis educativa, en lo que dice relación con la lectura, especialmente con la lectura de textos literarios, no tenga tanto que ver con la incorporación de las nuevas tecnologías en sí, cuanto con los profundos cambios que ellas implican y que significan Volumen 8, Número 3, Año 2008, ISSN 1409-4703 
un continuo e inestable proceso de reorganización y reubicación de saberes y sistemas de codificaciones, cuestión, que todavía no terminamos (o no empezamos) a asimilar adecuadamente. (Ostria, 2005, p. 2)

El grupo estudiantil tiene nuevos saberes, conocen otros códigos, poseen una información que sus docentes desconocen casi por completo; pero al mismo tiempo, este grupo tiene carencias, una de ellas es la falta de propiedad para leer textos literarios completos y además, disfrutarlos. Ello se debe a que dominan otra forma de codificar y decodificar mensajes. Dominan la codificación y decodificación de los juegos de vídeo, de ver televisión, chatear con sus amigos y oír el último $C D$ de su grupo favorito, simultáneamente. Lo decodifican, lo entienden y lo disfrutan; actos que no realizan con los textos literarios porque no saben ni se les ha enseñado cómo hacerlo. Por eso Ostria dice que el problema no está tanto en el advenimiento de las tecnologías sino en los cambios en la codificación y decodificación de mensajes. La juventud de hoy está acostumbrada, educada e inmersa en la cultura audiovisual, hay imágenes que se mueven, les hablan, les apuntan con armas virtuales. Descifran el código audiovisual, son hábiles con la motora fina en sus juegos de vídeo.

Dice Jesús Martín-Barbero, recordando las investigaciones del Margaret Mead, que la juventud actual vive el futuro que estaba escrito en los libros de ciencia ficción que leían sus abuelos y padres. Esta juventud es parte de la cultura prefigurativa que explica Mead. Esta es una cultura "que remite entonces a un aprendizaje fundado menos en la dependencia de los adultos que en la propia exploración que de los habitantes del nuevo mundo tecnocultural hacen de la imagen y la sonoridad, del tacto y la velocidad" (Martín-Barbero, 2002, p.2)

Son jóvenes que desde la niñez, gracias a estos medios tecnológicos, conocen el mundo de los adultos y son conscientes que el saber no se encuentra únicamente en la escuela y en la figura del cuerpo docente. El saber lo toman de otros medios, de su relación con la tecnología y del manejo de la misma. Por ello la adolescencia tiene una forma de acercarse al mundo distinto al de sus mayores, gracias a la cultura tecnológica y a la información que recibe de la televisión y las redes informáticas. Ello lo hace poseedor de una sensibilidad distinta, marcada por una

...doble complicidad cognitiva y expresiva: es en sus relatos e imágenes, en sus sonoridades, fragmentaciones y velocidades que ellos encuentran su idioma y su ritmo. Volumen 8, Número 3, Año 2008, ISSN 1409-4703 
Estamos ante la formación de comunidades hermenéuticas que responden a nuevos modos de percibir y narrar la identidad, y de la conformación de identidades con temporalidades menos largas, más precarias pero también más flexibles, capaces de amalgamar, de hacer convivir en el mismo sujeto, ingredientes de universos culturales muy diversos. (Martín-Barbero, 2002, p. 5)

Su acercamiento al mundo del saber formal, encerrado en las cuatro paredes de un colegio, tiene que transformarse, porque la sensibilidad de la adolescencia, su acercamiento al mundo, su acercamiento al saber, se ha transformado.

En otras palabras, su capacidad para descifrar códigos se encuentra en el campo de la actividad audiovisual, no en el impreso de los textos literarios. No tiene un entrenamiento para hacerlo porque se ha educado para descifrar otro tipo de códigos.

En conclusión, al no haber educación de la lectura en la casa y al tener un acceso restringido a los libros en la escuela, pues se leen muy pocos en clase y las bibliotecas escolares están poco surtidas o en ocasiones son inexistentes, la práctica de lectura es poca y pobre. Esta generación de nativos digitales crece sin aprender a descifrar el código escrito e impreso en libros, por eso tiene una capacidad limitada para leer un texto, comprenderlo más allá de lo literal y disfrutarlo.

Una tercera razón por la que los jóvenes no se acercan a textos de literatura que se tienen que leer en el colegio, obedece a que la lectura en el colegio es de carácter obligatorio. Sus lecturas están comprendidas en listas limitadas que son poco motivadoras para la edad y los conocimientos de la juventud. Dice Ostria: "Por otra parte, los profesores de Castellano se quejan continuamente del poco entusiasmo que despiertan en los alumnos los textos recomendados en los programas oficiales" (Ostria, 2005, p. 2).

Como apunté antes, Daniel Penac (1992) y Jorge Luis Borges (1988) afirman categóricamente que la lectura no puede ser obligatoria. Es un acto de placer, de amor y diversión. El juego, el amor y la diversión no se realizan por obligación, se llega a ellos por convencimiento, por elección personal, no por imposición, miedo y autoridad.

La lectura cumple el mismo papel que el amor y el juego, por lo tanto, al ser obligatoria se convierte en una amenaza para los estudiantes; si no leen obtienen malas notas en los exámenes, si no saben identificar el ambiente, los narradores, los espacios, y el código apreciativo de un texto literario, las calificaciones se bajan y se corre el riesgo de perder la materia. 
Además, los textos literarios que se leen en el sistema educativo costarricense fueron escogidos por su pertenencia al canon literario, por su importancia para el desarrollo de la literatura universal y por su representatividad para ejemplificar un movimiento o un género; no fueron pensados para interesar al estudiante, para acercarlo a un mundo nuevo que se refiera a sus intereses, a su edad y a sus escasos conocimientos en la materia. Finalmente, como se apuntó con anterioridad, estos textos se leen con un ánimo de analizar y no está encauzada a que el grupo de estudiantes la disfrute, interprete y conozca. Dice Alonso sobre la manera en que hay que acercarse a un texto literario: "Un libro cobra vida cuando un lector lo coge, lo hace suyo, lo cambia, lo tira: es, en fin, un acto de pasión. Ahí reside, precisamente, la magia de la lectura. En la lectura no hay entrega, sino participación" (Alonso, 2007, p. 2).

Por supuesto que los jóvenes que asisten a nuestros colegios no sienten el deseo de leer por gusto, no hacen suyo el texto, no los atrapa la magia y el acercamiento que se hace a ellos en las aulas los alejan aún más del disfrute. . Esto se debe a que no se les inculca el hábito de la lectura, no se les ha enseñado el código y para colmo se los obliga con textos que no son adecuados ni para su edad ni sus intereses.

\section{¿Qué se lee en el colegio? Entre la teoría y la experiencia}

Carlos Lomas (1999) y Josefina Prado (2004) identifican tres formas de enseñar la literatura a lo largo de la historia del siglo XX en los colegios de secundaria: la historicista, la estructuralista formal y la visión teórico-crítica. La primera se centra en el emisor (autor), la segunda en el mensaje (texto) y la tercera en el receptor (lector).

La primera de ellas, basada en el autor, se conoce como enfoque historicista y se caracteriza por presentar en el aula a los autores y obras que sean representativos e importantes para una nación. Con este modelo se busca "crear una conciencia nacional con el conocimiento de las obras y los autores más representativos de cada país" (Prado, 2000, pp. 330-331). El fin de la enseñanza y aprendizaje de la literatura, desde la perspectiva del historicismo, buscaba que el estudiante tuviera un conocimiento memorístico de la historia literaria en orden cronológico, desde sus orígenes hasta nuestros días. En él, se debía conocer y aprender los autores y sus datos biográficos, sus obras literarias con sus rasgos estilísticos más sobresalientes, los movimientos y géneros más representativos. Este enfoque prevaleció hasta los años setenta del siglo $X X$, aunque en la actualidad aún se encuentran rasgos de este enfoque en los programas de estudio. 
El modelo basado en el mensaje se conoce como modelo textual y tuvo su desarrollo en los años setenta, con el auge y fortalecimiento del formalismo y el estructuralismo formal. Este modelo estaba basado en la búsqueda de la literariedad del texto. Dice Carlos Lomas (1999) que el "análisis científico de los textos a través del comentario explicativo del enseñante se convierte en una enseñanza cuya utilidad es tanto explorar la función poética del lenguaje literario como crear actitudes de aprecio hacia las obras literarias" (Lomas, 1999, p. 99), este tipo de enfoque convive con el historicista en muchas de las aulas de la Educación General Básica.

En la década de los ochenta, el "acento se pone no tanto en el texto como objeto de estudio en sí mismo como en los fines de la educación literaria y en el estudio de las estrategias didácticas para contribuir a la adquisición de hábitos lectores en adolescentes y jóvenes" (Lomas, 1999, p. 99). La literatura deja de pensarse como en el estudio de textos consagrados por la tradición académica y se convierte en una herramienta comunicativa mediante la cual el grupo de adolescentes "intentan dar sentido a la propia experiencia, construir su identidad individual y colectiva y utilizar el lenguaje de modo creativo" (Lomas, 1999, p. 99). Este enfoque está basado en el receptor/lector adolescente y busca que desarrolle su competencia literaria; se conoce como modelo basado en el conocimiento de los textos.

La competencia literaria es concebida "como una competencia lectora, con estrategias que permitan al lector la construcción del sentido y la comprensión e interpretación de textos, así como la expresión creativa mediante la manipulación y producción de textos" (Prado, 2000, p. 333). El enfoque basado en el receptor busca desarrollar la lectura así como la construcción de sentido del texto por parte del grupo de jóvenes estudiantes para que haga suyo el texto y lo sienta propio y no impuesto como un conocimiento que viene de fuera y que debe aprender porque un docente o un libro de texto así se lo dicen.

Estos tres enfoques han estado presentes a lo largo de la historia en la enseñanza de la literatura en Costa Rica; actualmente, el Plan de Estudio de Español para el Tercer Ciclo de la Educación General Básica (2005) presenta contenidos que implican un análisis estructuralista formal, basado más en el texto que en el lector; se eligen los textos de forma historicista, siguiendo un orden cronológico y representativos de un género o movimiento; el aspecto estructuralista se aprecia en los contenidos que se estudian en sétimo año y que se transcriben a continuación. Este aspecto estructuralista de los contenidos ha sido estudiado en varios Trabajos Finales de Graduación, donde se reconoce que la mayoría de los Volumen 8, Número 3, Año 2008, ISSN 1409-4703 
contenidos tienden a dirigir el análisis hacia el aspecto formal del texto y no al contenido desde el punto de vista sociocríco. (Revisar: Brenes y otras, 2003; Chen y Muñoz, 2006; Aragonés y otras, 2007; Arias y otras, 2007 y Ramírez, 2006, 2007)

- Narrador: Tipos (omnisciente, testigo y protagonista); visiones (narrador>personajes, narrador < personajes, narrador=personaje).

- Organización secuencial de la historia narrada (lineal o perturbada).

- Código apreciativo (valoración de las partes del mundo mostrado). registros del habla (lenguaje culto, coloquial, técnico, literario).

- Los estilos directo e indirecto, planos.

- Mundo mostrado: espacios (físico, ético, religioso, jurídico, educativo, económico, político, social, ecológico o psicológico, cuando los haya). Personajes (lo que dicen ser y lo que hacen), su interacción con los otros, su código apreciativo (valoración del mundo mostrado).

- Relaciones del texto con el contexto sociocultural, con los géneros y los movimientos literarios. (MEP, 2005, p. 38)

Estos contenidos que se estudian en las aulas costarricenses buscan un análisis estructuralista formal buscando estudiar el texto desde su forma, además se aplican a todos los textos literarios que se estudian en el colegio, no solo en sétimo nivel, sino que de forma similar en octavo y noveno, sin importar si el lector/estudiante se enfrenta a una leyenda del Romanticismo de Gustavo Adolfo Bécquer o a una novela costarricense de finales del siglo $X X$, de Fernando Contreras, Única mirando al mar.

Estos contenidos no solo aparecen en los programas, sino que se aplican en las aulas y los docentes los repiten a sus estudiantes año tras año. Además, aparecen explicados en los libros de texto que algunos usan o en cuestionarios que elaboran para que el grupo de estudiantes responda con el fin de que encuentre en los textos literarios narrador, tiempo, espacio, personajes estilo y demás. Estos prácticas son observadas por la profesora Catalina Ramírez (2006) quien en el artículo publicado en la Revista de Filología, Lingüística y Literatura aduce que cuando el personal docente de español no cuenta con el libro de texto, construye cuestionarios para que los estudiantes encuentren la estructura formal de lo que leen y el cuestionario sigue las mismas pautas de los libros de texto y se usa el mismo sin importar la diferencia de autor, género o movimiento. 
Lo extraño de estos contenidos de corte estructuralista formal es que no se relacionan con el objetivo general para la lectura de textos literarios, que el mismo Ministerio de Educación Pública propone y que aparece en el mismo documento; según se lee el objetivo general es:

Propiciar un acercamiento plural, creativo y crítico a la lengua literaria como un sistema ficcional, connotativo, plurisignificativo, dialógico-cultural, que propicie la sensibilidad y el disfrute de la lectura, mediante el conocimiento y la valoración de la literatura costarricense e hispanoamericana (MEP, 2005, p. 38).

Como se puede observar, este apela más a la interpretación del receptor (lector) que al análisis del mensaje (texto). Mientras los contenidos apelan al análisis estructural, el objetivo general busca la interpretación y comprensión, así como el establecimiento de un diálogo con el texto.

Se observa que en los planes de estudio vigentes, la parte que corresponde al estudio de los textos literarios presenta incoherencias al proponer el acercamiento al texto desde dos enfoques: el estructuralista y el basado en el conocimiento de textos. De acuerdo con la práctica habitual de los docentes en el aula, que ha sido estudiada y observada en distintos trabajos de investigación elaborados en la Licenciatura de la enseñanza del Castellano y Literatura de la Universidad de Costa Rica, lo que priva al acercar al joven a la literatura, es la ejecución de los contenidos que propone el Plan de Estudio y no del objetivo. (Brenes y otras, 2003; Palacios y Picado, 2004; Méndez, 2005 y Ramírez, 2006, 2007).

Este acercamiento, basado en los contenidos, ha demostrado no ser efectivo: los grupos de jóvenes no solo se resisten a leer sino a efectuar los análisis estructurales solicitados por sus docentes. Se ha comprobado, por observaciones hechas en el aula por esta investigadora, por las tareas que entregan a sus docentes que estos análisis son bajados de los múltiples sitios de Internet que los ofrecen o de los mismos libros de textos, que edición tras edición los repiten (Ramírez, 2006, 2007).

Como apunté anteriormente, no solo el acercamiento en el aula aleja al joven de la lectura, lo hacen también los mismos textos literarios que tiene que leer. Los textos que componen la lista de lecturas obligatorias para el Tercer Ciclo, están escogidos por un grupo de expertos en Literatura que desconocen la realidad de las aulas y el cambio que ha sufrido la nueva generación gracias a los avances tecnológicos antes comentados. Estos expertos, para elaborar las listas se basan en la concepción de la década de los setenta del Volumen 8, Número 3, Año 2008, ISSN 1409-4703 
modelo historicista, eligiendo textos que pertenecen al patrimonio cultural de la humanidad, "obras consagradas por la historiografía erudita y por la enseñanza universitaria" (Prado, 2000, p. 331) que no se acercan a las necesidades, intereses y gustos de la juventud actual, lectores incipientes e inexpertos.

Esta elección tampoco contempla la recomendación que apunta Lomas (1999) cuando aconseja se debe hacer desde tres perspectivas: primero tomando en cuenta el prestigio cultural del texto; segundo con criterios pedagógicos y tercero teniendo en cuenta el deseo del grupo de jóvenes "por lo que se les debe dejar leer cualquier cosa ya que lo importante es que lean y que les gusta lo que leen" (Lomas, 1999, p. 91).

Los textos que se leen en las aulas se eligieron tomando en cuenta solo la primera perspectiva: su prestigio cultural; las otras dos: los criterios pedagógicos y el gusto del grupo de estudiantes no se tomaron en cuenta. No voy a nombrar todos los textos literarios que los adolescentes tienen que leer en la educación secundaria costarricense, pues las personas que trabajan en la materia de español los conocen bien. Sí puedo decir que pertenecen al canon literario universal, provenientes de diferentes épocas y contextos y que narran hechos y acciones que no tiene referente para el estudiante de secundaria. Me interesa destacar tres ejemplos de novelas que se leen en los tres primeros años de educación secundaria. En sétimo nivel, cuando el estudiante tiene entre 12 y 13 años, se inicia con Marianela, de Benito Pérez Galdós; en octavo nivel se sigue con La Vorágine, de José Eustasio Rivera y en noveno con Fernando Contreras, autor de Única mirando al mar.

Después de terminar la educación inicial básica, donde se leen libros infantiles, con una linealidad cronológica y secuencial, con un vocabulario básico y dirigidas por docentes mediante actividades lúdicas y creativas (Méndez, 2002) abruptamente se le presenta al joven de doce y trece años Marianela, de Pérez Galdós. Es un salto al abismo de la lectura y del juego con textos como Pantalones cortos, de Lara Ríos, Pedro y su teatrino maravilloso, de Carlos Rubio o El Príncipe Feliz, de Oscar Wilde, se brinca al realismo español, siglo XIX, con una estética, un lenguaje y un argumento profundo, llenos de conceptos implícitos, anclado en la historia de la literatura, ejemplo de un tipo de estética y escritura que el joven estudiante de secundaria nunca en su vida había siquiera imaginado que existía, pues ni en la educación primaria se lo enseñaron y por su cuenta, difícilmente se habría acercado a este tipo de texto.

Además de lo anterior, se pretende hacer un acercamiento de análisis literario estructuralista formal, más propio de los estudiantes universitarios de Filología que de Volumen 8, Número 3, Año 2008, ISSN 1409-4703 
jóvenes lectores inexpertos que sin razón clara deben caracterizar personajes desde la perspectiva física, moral, emocional y psicológica; descubrir el ambiente que puede ser espacial, psicológico, educativo y muchos más; identificar el estilo en las intervenciones de los personaje, rastrear el intertexto del texto en estudio, relacionar la obra leída con contexto en que fue producida, encontrar esos marcadores del contexto en la novela que estudian y además, para mi sorpresa e incomprensión, identificar el "código apreciativo" del texto. (MEP, 2005).

Para terminar de adornar las dificultades que implican la comprensión de la novela Marianela, el docente consciente debería guiar al joven hacia la comprensión del concepto de belleza que maneja Galdós. Este es un concepto que se remonta a Aristóteles y que genera dificultades no solo para su explicación sino para la comprensión. En esta novela, la belleza física está ligada a civilización, educación y conocimiento, presentes en los personajes de Pablo y Florentina, y la fealdad se relaciona con ignorancia y barbarie, reflejado en el personaje de Marianela. Así que la comprensión y el acercamiento al texto es de una profundidad y complejidad filosófica al que antes nunca estuvo expuesto, y encima aparece un concepto de belleza anclado en la tradición clásica fuera del alcance de sus conocimientos y muy diferente al que conoce y que se propaga por los medios de comunicación masiva. En conclusión, la lectura se les hace pesada y no llegan a comprender el porqué de las acciones y hechos, no aprecian la defensa que hace Galdós del conocimiento y quedan con la idea que la belleza física y no la intelectual es la que lleva al amor.

Estos son los problemas que presenta el acercamiento a Marianela, pero si se piensa en la novela de octavo año, La Vorágine, las dificultades se multiplican, gracias a la introducción de tres aspectos más desconocidos por el joven estudiante: el vocabulario compuesto por colombianismos de principios del siglo XX, la introducción del personaje de la selva y la ruptura de la secuencialidad lógica del relato.

En la investigación dirigida para obtener el grado de licenciadas en la Enseñanza del Castellano y la Literatura, las investigadoras Cynthia Muñoz y Cristina Chen (2006), intentaron motivar la lectura de esta novela, a estudiantes de octavo año del Colegio Técnico Don Bosco, introduciendo el juego escénico. Luego de un largo trabajo para organizar, actuar y presentar una dramatización informal sobre el texto en estudio, comprobaron que mediante el uso de esa técnica no fue posible motivar la lectura de la novela y los estudiantes confesaron que no la leyeron y que para preparar el papel en la dramatización Volumen 8, Número 3, Año 2008, ISSN 1409-4703 
solo conocieron la parte que les tocó dramatizar, ya fuese leyendo resúmenes o con lo que les contaron algunos de sus compañeros (Muñoz y Chen. 2006). Es más, al finalizar la presentación, manifestaron sentirse motivados a estudiar actuación pero de ninguna manera a leer el texto de Rivera.

Por otra parte, el estudiante de décimo año de un colegio de Turrialba, Marcelo Guevara, escribe en el periódico La Nación, acerca de las lecturas obligatorias, que se hacen en los colegios y sobre La Vorágine apunta:

Pero si analizamos profundamente el asunto, los estudiantes no cargamos totalmente la responsabilidad de esto. En un mundo cambiante como el actual lleno de distracciones y estereotipos, no creo que una novela como La Vorágine, que trata las inhumanas acciones que se daban en las chaucheras, sea un asunto que les importe a los alumnos modernos. Otros temas que, si bien es cierto es "bueno" saber, no son importantes ni traerán gran beneficio a futuro. (Guevara, 2008, p. 39a)

Nadie duda del valor literario de las dos novelas comentadas, de su importancia para la historia de la literatura universal, pero es claro que un joven del siglo XXI, no solo no las comprende, sino que no les encuentra importancia para su formación.

Finalmente, en noveno año se acercan a la novela Única mirando al mar, del costarricense Fernando Contreras. Con este texto la actitud de los estudiantes cambia. En un encuentro entre esta articulista y los estudiantes de noveno año del la Unidad Pedagógica de Cuatro Reinas, en Tibás (2006), la mayoría de los jóvenes manifestaron haber leído y disfrutado la novela. Las razones que adujeron fueron que el texto les era cercano, que las acciones ahí retratadas se relacionaban con sus vidas, que conocían los lugares mencionados y que tenían un conocimiento de la problemática del basurero de Río Azul, tema que trata el texto. Además dijeron que sacaron de ella importantes reflexiones personales sobre el problema de la contaminación en el país.

Esta novela, escrita por un costarricense, a finales del siglo $X X$ que se refiere a temas cotidianos y actuales para los jóvenes, cala en ellos, la leen, no por el próximo examen que se acerca, sino por el placer que les provoca y por la proximidad e interés de los temas que en sus jóvenes mentes despierta.

Pero esta actitud de gusto y aceptación solo se observa con la lectura del texto literario de Contreras, los otros textos impuestos como obligatorios no obtienen la misma aceptación por parte de los estudiantes y al no interesarles no los leen, copian los resúmenes de Volumen 8, Número 3, Año 2008, ISSN 1409-4703 
Internet y estudian para el examen el análisis estructural que presenta alguno de los libros de texto que existen en el mercado costarricense y que traen desarrollados los contenidos apuntado por el Plan de Estudio. Por eso hay una queja constante de docentes y estudiantes. Los primeros porque dicen que el estudiante de secundaria no lee y los segundos, porque lo que los obligan a leer no les gusta ni les interesa.

La pregunta que surge es ¿qué hacer para que el joven adolescente se enamore de la literatura y tome con placer un texto literario?

\section{¿Cómo enseñar textos literarios en la época tecnológica? Experiencias a manera de propuesta}

Para iniciar este apartado, citaré nuevamente al profesor Mauricio Ostria, quien se hace una pregunta interesante sobre el fenómeno de la lectura y que contesta de la siguiente forma:

¿Quién les ha preguntado a los niños, a los estudiantes por sus gustos lectores, por aquello que les gustaría encontrar en los libros? Es frecuente oírlos referirse a las lecturas obligatorias como aburridas, latosas. Fundados en esta experiencia, propusimos investigar los hábitos y preferencias lectoras de los estudiantes a través de un programa de encuestas, entrevistas y ejercicios, que permitieran, por un lado, observar, describir y evaluar los hábitos de lectura, y, por otro, percibir los gustos y preferencias literarias. Los resultados se contrastarían con las lecturas canónicas de los programas oficiales de enseñanza. La investigación concluiría con la construcción de un corpus que compatibilizara las preferencias de los jóvenes con los objetivos educativos contemplados en los planes oficiales. Finalmente, un informe propondría medidas tendientes a corregir, desarrollar y fomentar la competencia lectora del universo investigado, así como estrategias que permitieran a los profesores de Literatura ensayar nuevas metodologías para la enseñanza, especialmente en el trabajo de comentario e interpretación de textos. El objetivo último de este proyecto era fomentar la lectura comprensiva y gozosa. (Ostria, 2005, pp. 2-3)

En esta cita Ostria toca un punto importante: las lecturas que se hacen en la educación secundaria deberían desarrollar la competencia lectora y no la competencia de analistas literarios. Por otro lado, los textos literarios que se les imponen a los estudiantes, tendrían 
que estar encaminados a que aprendan a leer, a comprenderlos, interpretarlos y a disfrutarlos y no a que aprendan el canon literario o el análisis literario. Eso sí, esta selección no implica que se descuide la calidad literaria. Es posible escoger textos con temas que les interesen, que les enseñen la vida en el mundo que les tocó vivir sin menospreciar la calidad literaria,

A través de la lectura se consigue el desarrollo de la capacidad de análisis y del sentido crítico. No se puede hacer una lectura bebiendo el libro como quien bebe las imágenes de la televisión; el lector tiene que analizar y tomar partido por lo que está leyendo. (Alonso, 2007, p. 1)

Hay que enseñar a estos jóvenes a leer los textos literarios y hacerlos comprender que este tipo de lectura no es el mismo que usan para leer una película en DVD o descifrar un juego de play station; el docente necesita enseñarlos a crear las imágenes en su imaginación, a comprender las acciones mediante las palabras y a disfrutar comprendiendo las ideas. Por eso, para que comprendan la lectura e imaginen el desarrollo de la trama es necesario presentarle a los estudiantes lecturas que estén cercanas a ellos, que los atrapen con el fin de desarrollar la competencia lectora.

Una forma de lograr este desarrollo de la imaginación y la comprensión es acercarlos a la lectura mediante actividades lúdicas y creativas que les ayuden a visualizar lo que ocurre por medio de las palabras. Para indagar la forma de abrir la comprensión de los textos literarios impresos a los jóvenes que estudian en el Tercer Ciclo de la Enseñanza General Básica, es que he puesto en práctica diferentes actividades creativas y lúdicas en los distintos cursos que he impartido en la Universidad de Costa Rica y que luego, algunos de los estudiantes, han llevado a los colegios cuando les ha tocado impartir lecciones.

El objetivo de proponer estas prácticas de lectura asociadas al juego y a la creatividad es mostrarles a los estudiantes de colegio que la literatura es algo más que un largo y aburrido análisis, que lo dicho por los textos son situaciones que los implican, los ayudan a conocer un mundo interesante y placentero y que con ella pueden comprender mejor el mundo y disfrutar de momentos de placer y diversión. Otro objetivo que se propone este tipo de técnica es despertar la competencia lectora, haciendo que el acercamiento al texto sea un diálogo entre ellos y este. Estas actividades buscan cumplir no solo con el objetivo propuesto por el Ministerio de Educación, sino desarrollar la competencia lectora, para que comprendan, interpreten y dialoguen con lo que se lee.

Volumen 8, Número 3, Año 2008, ISSN 1409-4703 
Estas técnicas serían mucho más efectivas si se aplicaran a obras literarias que fueran del agrado de los estudiantes y no a las que actualmente tienen que leer, pero se hizo un intento con La Vorágine, texto que se acaba de comentar como complicado y que los mismos estudiantes consideran feo e ilegible. Para ello se siguieron las siguientes pautas.

Como se sabe que no leen el texto completo, se dividió en diez secciones, ya que en el curso se tenía a diez estudiantes, buscando los temas más representativos que se desarrollan, estos fueron: la huida de Alicia y Arturo, la llegada de Alicia y Arturo a la hacienda La Maporita, la quema de La Maporita y la huida de Arturo y algunos más a la selva, el tránsito por la selva y el encuentro con los guajiros y luego con Heli Mesa y sus hombres, la historia de Clemente Silva, la llegada a las barracas del Váquiro y Amyra, la explotación del caucho, la muerte del Cayeno y la búsqueda de Alicia por parte de Arturo.

Una vez seleccionados los fragmentos se le entregó uno a cada estudiante del curso, se les dejó de tarea leer el fragmento y a la lección siguiente se les propuso hacer un libro ilustrado. En este caso, como el grupo era pequeño, compuesto por diez estudiantes, nueve mujeres y un hombre, cada estudiante se encargó de ilustrar el fragmento. Como el grupo estudiantil que compone cada clase en los colegios suele ser más numeroso se pueden organizar en parejas y además el texto se puede fragmentar mucho más. Cada estudiante, con su fragmento leído explicó a la clase lo que iba a dibujar. Una vez que todo el grupo contó su fragmento se pusieron a trabajar. La directriz que se les dio fue elaborar un dibujo del fragmento y pintarlo con acuarela o témpera, siguiendo la técnica que quisieran y representando el fragmento desde la óptica que más les gustara. Para dibujar, la profesora proporcionó a cada una un pedazo de cartulina reciclado y aportó algunas témperas y pinceles que se completaron con las que los mismos estudiantes trajeron de sus casas. El tiempo para ejecutar cada una de las ilustraciones fue de tres lecciones y quienes no lo terminaron se lo llevaron a la casa para terminarlo.

Una vez que los dibujos estuvieron listos, la docente los recogió, los escaneó y los organizó en una presentación de power point que presentó a la clase. Cada dibujo mostraba una leyenda que lo explicaba y que fue escrita por quien hizo el dibujo. Este es el resultado del libro ilustrado de La Vorágine Descargar.

Una vez escaneado el libro ilustrado se expuso ante la clase; el siguiente paso consistió en que cada estudiante/ilustrador narrara los hechos del fragmento que le correspondió, así como responder a las preguntas de la docente sobre las características y acciones de los personajes, el ambiente y otros temas que corresponden al análisis Volumen 8, Número 3, Año 2008, ISSN 1409-4703 
estructural del texto que solicita el programa de estudio del Ministerio de educación Pública. Además explicaban lo que sentían respecto al fragmento, lo relacionaban con su realidad e interpretaban alguno de los personajes o acciones, todo ello también guiado por preguntas de la docente, que los hacía adentrarse un poco más en la comprensión e interpretación del texto.

Esta parte de la actividad se trabajó de forma oral, con el fin de ir desarrollando la expresión oral de los estudiantes quienes tienen problemas para expresarse ante el grupo por la escasa práctica que de ella se hace en clase. Las preguntas de la docente tenían como finalidad no solo ayudarlos a adentrarse en el sentido del texto, sino que además buscaban motivarlos para que organizaran su discurso oral, incluyendo ideas y comentarios personales.

En cuanto a la representación gráfica que se hizo de los fragmentos, se observó que algunos plasmaban la acción de manera literal, lo que muestra que el artista solo captó las ideas claves de la acción; este es el caso de la primera de las ilustraciones, la huida de Arturo y Alicia.

En la cuarta ilustración que representa el viaje de Arturo y sus compañeros por la selva, también hay una interpretación literal de lo leído; aparecen representados todos los elementos de los que habla el fragmento: el bote en el que llegaron Arturo con sus compañeros, los indios guajiros, la aldea de los indígenas, el río y el bosque, pero en esta ilustración se observa además, un tímido intento por interpretar lo que significa este viaje. Esta interpretación se encuentra representada en el cielo color naranja que muestra, según la autora del dibujo, la sangre y las dificultades que se les presentaron a los viajeros.

Aunque el dibujo es una interpretación literal del suceso, la dibujante/estudiante quiso ir más allá e indicó mediante el cielo encendido un estado de ánimo, producto del viaje de los personajes. Ello muestra un inicio de interpretación de la realidad leída y un diálogo con el texto al representar, un estado de ánimo. 


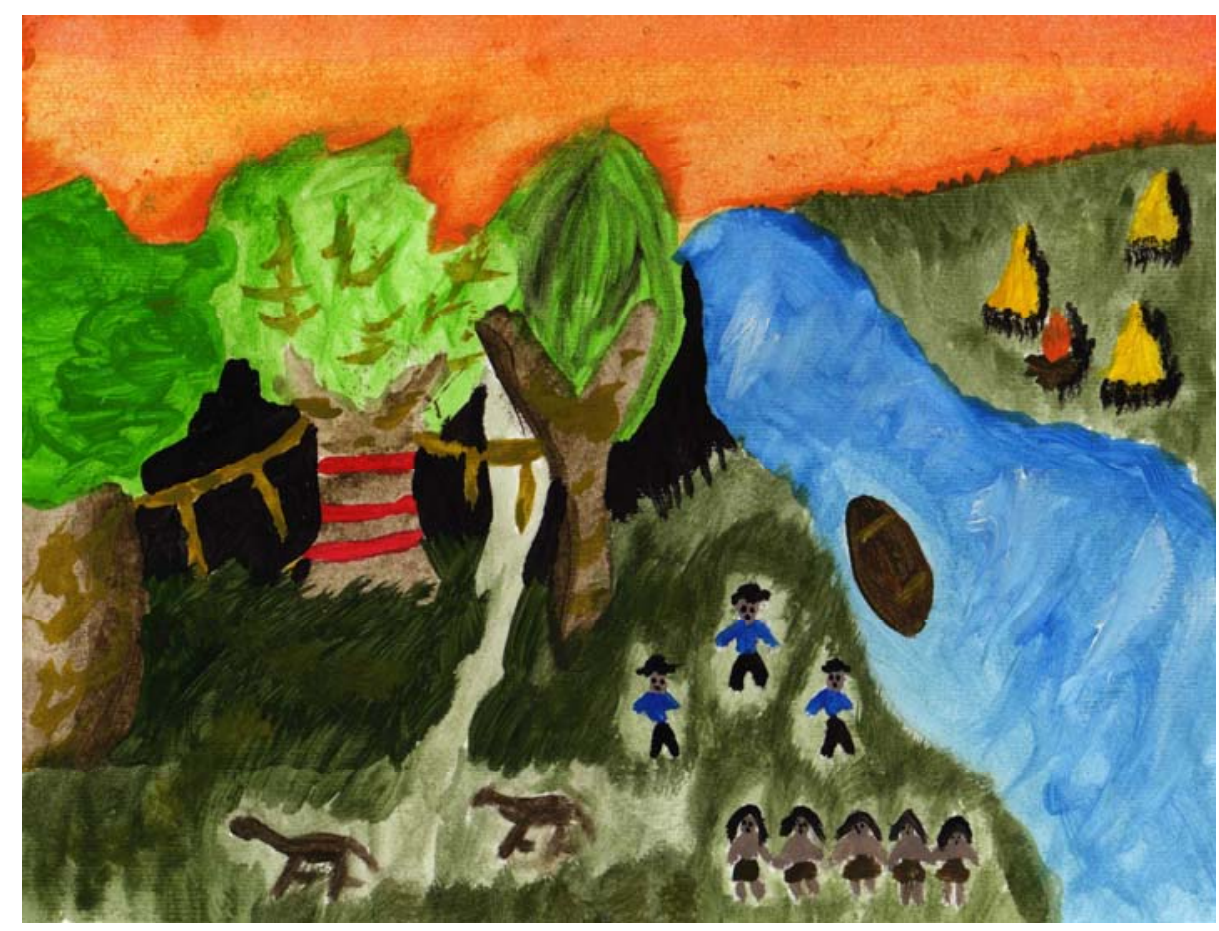

Arturo y sus compañeros encuentran a los indios guajiros

En la sexta imagen se muestra que la estudiante/ilustradora llegó más allá de la lectura literal del texto, al adentrarse en la interpretación e incluir elementos que no aparecen en el texto, pero que infirió, como son los dos ojos que observan a los personajes desde las copas de los árboles. Estos ojos, recorridos por venas rojas y hormigas caminando en las pupilas representan el poder vigilante de la selva sobre los protagonistas y la incapacidad de escapar de sus garras pues esta los vigila con dos enormes ojos que los persiguen todo el tiempo al atraparlos en múltiples dificultades.

Esta ilustración no solo muestra la acción, la aparición de Clemente Silva, sino que expone una interpretación de la lectora sobre el papel que desempeña la selva. Se pasa de la lectura literal para interpretar e inferir el papel de la selva sobre los personajes y la narración 


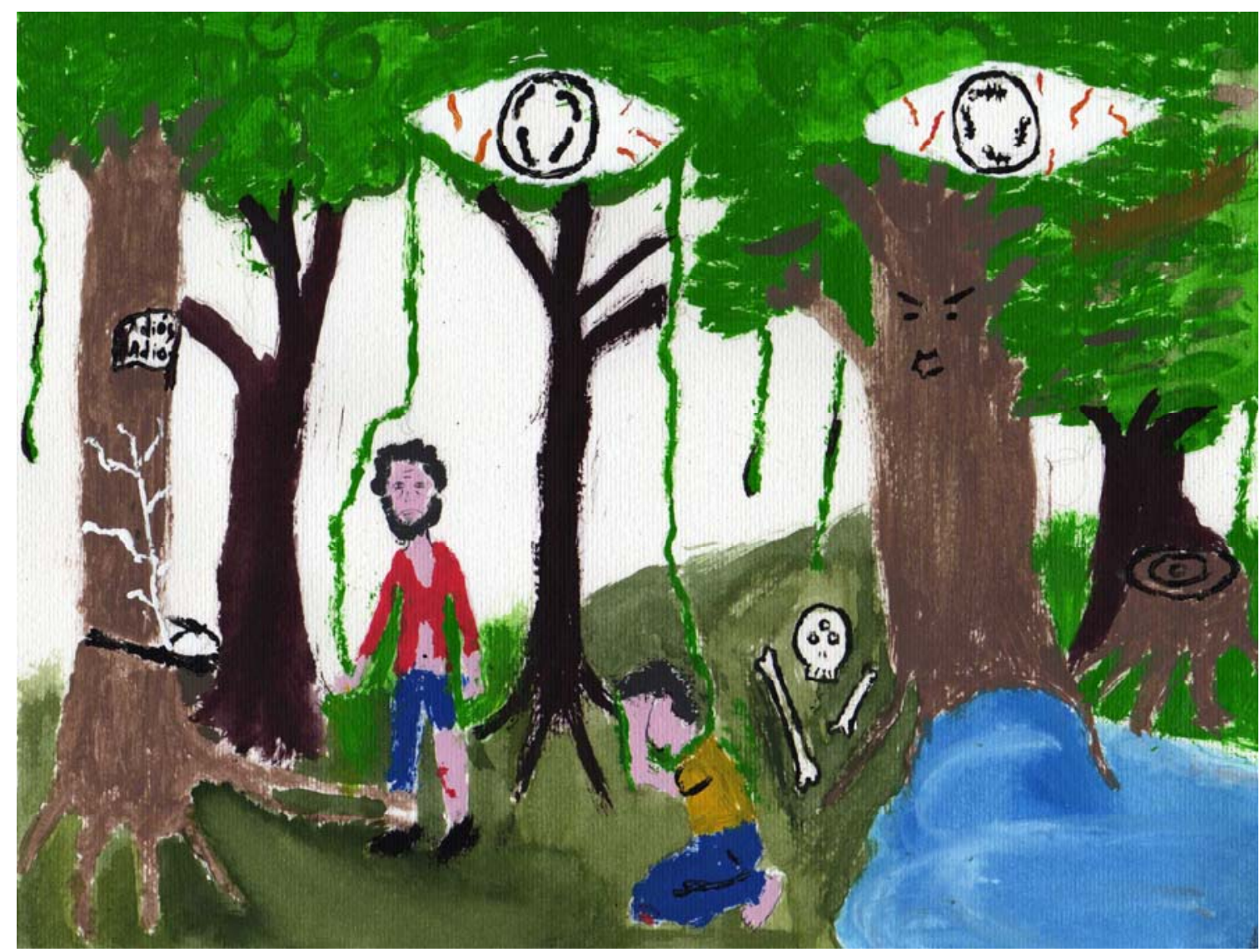

Historia de las desgracias del cuachero Clemente Silva

Otra ilustración para comentar es la penúltima que refiere la muerte del Cayeno. En ella la lectora/ilustradora presenta la acción literal pero a manera de síntesis y muestra la pelea y la muerte en una misma. Además, esta es la única de las ilustraciones donde la autora no se preocupó tanto por lo literal: poner cara a los personajes y representarlos de manera realista, sino que tiende a la abstracción y a representarlos con trazos simples pero sin buscar realismo. Hay una mayor inferencia e interpretación así como síntesis de la lectura del un fragmento.

Hay que recordar que cuando la docente dio las instrucciones para hacer las ilustraciones, solo pidió que representaran las acciones que leyeron de acuerdo con sus gustos y habilidades. Cada una de las estudiantes y el estudiante representó como más le Volumen 8, Número 3, Año 2008, ISSN 1409-4703 
gustó y como comprendió el texto. En esta actividad la docente pudo observar como algunos comprenden el texto solo en el nivel literal, mientras que otros pueden inferir e interpretar e incluso llegar a la síntesis. En el trabajo hecho por cada estudiante se pudo observar el nivel de lectura a que accede cada uno.

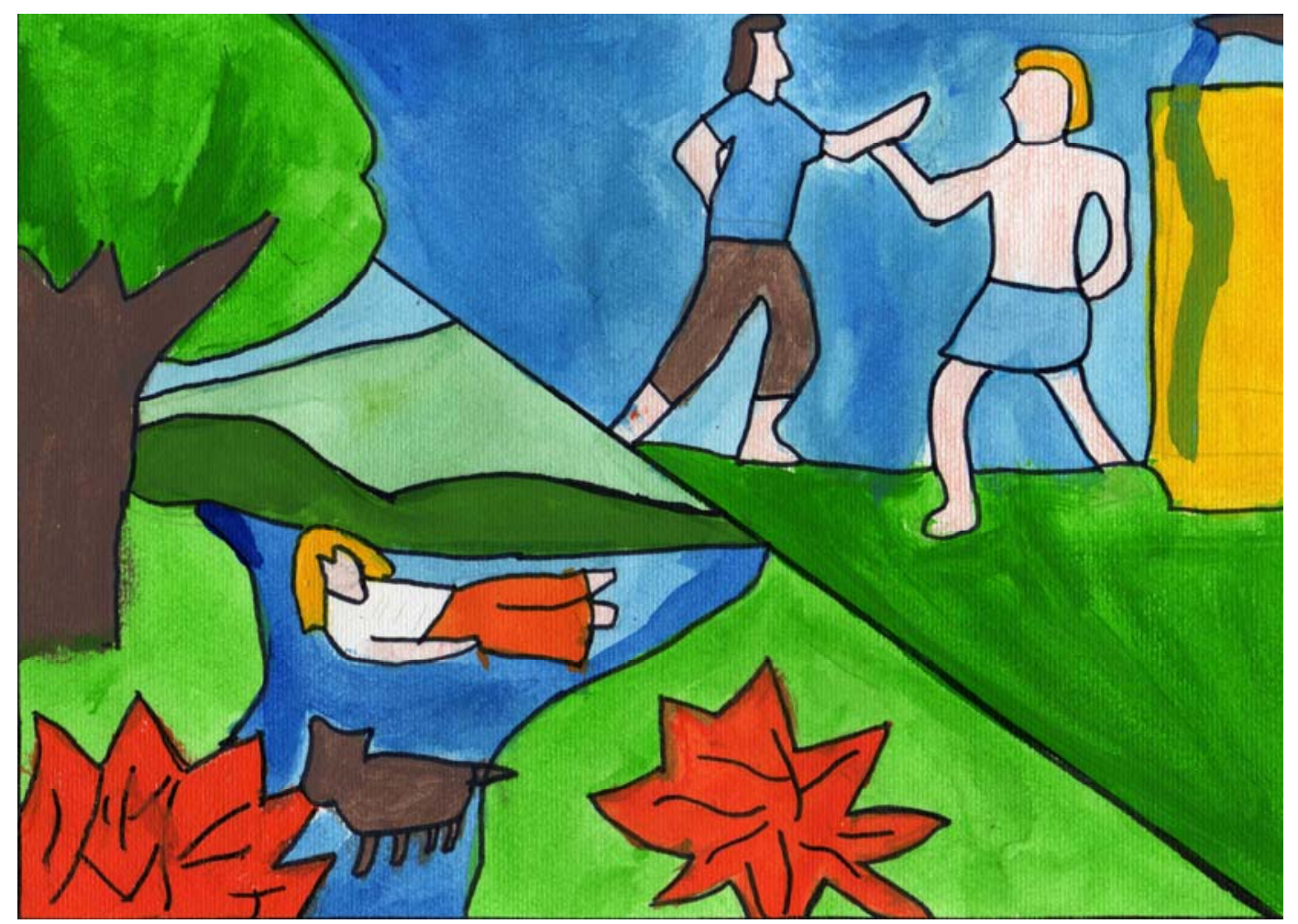

Últimos momento del Cayeno

El objetivo de la actividad del libro ilustrado fue promover la lectura por parte del grupo estudiantil. Se buscaba que los estudiantes leyeran la parte del texto que les correspondió, la comprendieran e interpretaran, así como que tuvieran un diálogo con el texto y desentrañaran los significados que este podía dar a cada uno. Es obvia la interpretación que se hizo, cada autor/ilustrador imaginó el mundo narrado, los personajes y las acciones y así las interpretó en la pintura que realizó, además algunos llegaron a efectuar una lectura que superó el nivel literal, llegando a la inferencia y la síntesis. 
La parte visual tiene para el grupo de estudiantes más significado que la lectura y al hacer un dibujo de una parte del texto pudieron ahondar más en el significado y recrearlo en una lámina de acuerdo con su creatividad e imaginación. Cada quien le dio una cara y un cuerpo al personaje y al ambiente que le correspondió representar.

Mediante esta actividad se pretendía lograr una inmersión del grupo de estudiantes en la lectura para crear un diálogo con el texto, de manera que sean ellos los interlocutores del texto, los personajes y la selva.

Otra actividad que busca acercar a los estudiantes a la lectura la realizó la profesora Roxana Lobo, docente en el Colegio Monseñor Odio de Desamparados. Esta docente, para trabajar el poema En la playa, de Claribel Alegría, elabora un Movie Maker, donde mediante imágenes ilustra el contenido del poema. Se puede observa el material a continuación

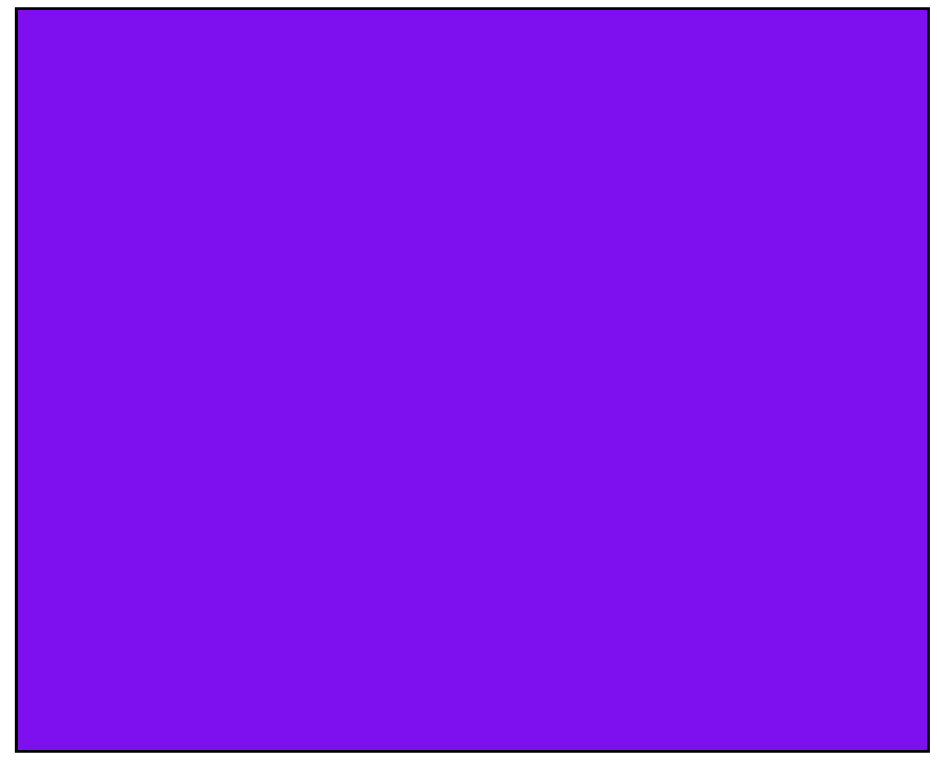

La profesora primero lee el texto, para que los estudiantes se hagan una primera idea del poema, luego pasa el material audiovisual, en donde se vuelve a leer el poema y se ilustra con imágenes. Este material pretende lograr una mayor comprensión del poema por parte de los estudiantes, al relacionar las palabras con imágenes.

Hay que recordar que los jóvenes que acuden hoy a las aulas son muy visuales, como se explicó anteriormente, por lo que escuchar el poema y ver las imágenes les permite comprender más y les proporciona herramientas para iniciar la interpretación del mismo a partir de la palabra y la imagen.

Como dice Josefina Prado, en estos momentos en que se ha perdido la costumbre de la lectura de textos impresos, lo que interesa es que el estudiante comprenda el texto, por lo Volumen 8, Número 3, Año 2008, ISSN 1409-4703 
que la enseñanza de la literatura debe estar centrada en la comprensión textual y "en la construcción del pensamiento cultural y la intertextualidad" (Prado, 2000, p. 333). No interesa que el estudiante haga un comentario del texto, basado en modelos estructuralistas sino en que llegue a tener una "formación literaria basada en el proceso activo de aprendizaje" (Prado, 2000, p. 333). Ello es posible al trabajar con este material de la profesora Lobo, pues las imágenes ayudan al joven a ver que el texto presenta otros mundos, otras culturas, otros momentos históricos: la posición de las mujeres chinas, musulmanas, la historia de Rafaela Herrera, el personaje de Lord Nelson. A partir de imágenes y texto los estudiantes adquieren conciencia del contenido del poema y pueden discutir sobre ello para conocer otros mundos y tomar una posición sobre temas importantes como el papel de la mujer en la sociedad.

En la actividad del libro ilustrado de La Vorágine se utilizó el dibujo y en el material sobre el poema En la playa se uso la imagen, la razón de la elección de las técnicas se apoya en lo que se comentó anteriormente, el grupo juvenil ha sido educado por los medios audiovisuales en los que la imagen predomina en sus vidas. La juventud de hoy aprendió a leer viendo imágenes en la televisión o en la pantalla del computador, por eso las dos actividades explicadas en este artículo buscaban una traducción del código escrito e impreso a un código que les fuera más cercano y comprensible

Con las dos actividades se pretende no solo que el grupo de estudiantes comprenda por sí mismo el texto sino que además lo haga activamente, se busca que la lectura tenga sentido, que además vaya desarrollando una competencia lectora y que se acerque a ella con actitud de placer y gozo.

Para que estas actividades sean más exitosas sería preferible no solo buscar métodos de enseñanza activa, lúdica y creativa, sino usar textos más cercanos a los intereses y actividades del estudiante tal y como aconseja el profesor español Carlos Lomas (1991). Como se apuntó anteriormente, los textos que se leen actualmente en los colegios costarricenses fueron escogidos por expertos estudiosos de la literatura, los cuales solo vieron la importancia de estos textos en el canon literario, basándose en una perspectiva historicista y promoviendo una acercamiento en el aula desde el comentario de texto estructuralista, actitud propias de la década de los setenta y que actualmente se sabe que no son efectivas para desarrollar la competencia literaria y el gusto por la lectura.

Si de verdad se quiere que quienes cursan su educación secundaria desenvuelvan una competencia lectora, comprendan e interpreten los textos con placer, es necesario partir de Volumen 8, Número 3, Año 2008, ISSN 1409-4703 
una forma distinta para elegir lo que van a leer, olvidando el historicismo y el canon, con el fin de situarse en la perspectiva del joven, sus gustos y necesidades.

Estas actividades presentadas acercan al joven a la lectura del texto literario, pero si se quiere una verdadera lectura es necesario adecuarse a los tiempos y a las nuevos enfoques pedagógicos y presentarle textos más cercanos a su época y a sus intereses, olvidándose del historicismo propio de la década de los setenta.

\section{¿Misión imposible?}

Es un hecho: la lectura, aún hoy en la época tecnológica, es una habilidad necesaria e importante de practicar. El mundo, a pesar de haber cambiado tanto en los últimos veinte años, todavía necesita de la lectura, quizá más que antes, pues para manejar muchos de los medios tecnológicos y digitales es imprescindible saber leer, comprender lo que se lee e interpretarlo. Por ello, en la educación formal no se puede descuidar esta habilidad y hay que enseñarla. Una de las formas de aprender a leer, a comprender y a interpretar el discurso escrito es mediante la lectura de textos literarios.

La lectura de textos literarios que se hace actualmente en los colegios pareciera no interesar al grupo de estudiantes ya que la forma en que se enseña no se adapta a los cambios de los tiempos. Docentes, investigadores e investigadoras y los mismos jóvenes apuntan que no leen textos literarios, pero sí leen otro tipo de textos que no son impresos y se caracterizan por ser tecnológicos, visuales, sonoros y animados. El grupo estudiantil posee una gran habilidad para leer y decodificar esos textos tecnológicos, pero no han desarrollado la habilidad de lectura de los textos impresos. Como se vio, no se han desenvuelto en esta habilidad, entre otras razones, por la falta de estímulo lector en el hogar, por actividades de lectura propuestas en el aula poco atractivas y por el escaso interés que le presentan las novelas que les imponen en el colegio como lectura obligatoria

En la escuela, donde se inicia esta actividad, se enfrentan a textos acordes con su edad e intereses y son desarrollados de forma creativa por sus maestras; cuando llegan al colegio se enfrentan a un cambio. Este cambio no es solo de metodología en el abordaje de los textos, sino en el tipo de lecturas que pasan de la fantasía y los temas que le son conocidos a lecturas de textos alejados en el tiempo, en el lenguaje y en la temática. Se enfrentan a textos importantes para la ejemplificación de la literatura universal, de los géneros y movimientos literarios que se han dado en la historia, pero sin relación con la situación vital de los jóvenes. Estos textos no los interesan, no los atrapan en la lectura. 
Además, estos textos literarios, ajenos al estudiante en cuanto a sus contenidos e intereses, se abordan en el aula desde la teoría del estructuralismo formal. Es un abordaje que busca formar críticos literarios o especialistas en literatura y no en nuevos lectores, capaces de comprender e interpretar un texto. El acercamiento que se trabaja en el aula no fomenta el placer por la lectura, la interpretación personal y la creatividad de los jóvenes que empiezan a formar su gusto literario. Se les debe acercar a todos los textos literarios, abrirles el espectro y como dice Lomas "se les debe dejar leer cualquier cosa ya que lo importante es que lean y que les guste lo que leen" (Lomas.1999.91), se busca que se enamoren de la literatura, jueguen con ella y la disfruten, no que sean expertos literarios.

Aunque los textos leídos actualmente no son del agrado de los jóvenes, es posible pensar actividades lúdicas y creativas que los acerquen a la lectura, que les muestren la capacidad de la literatura para producir placer y conocimiento de manera agradable y adecuada a sus intereses y conocimientos. Por eso se presentaron dos actividades basadas en la imagen, para que se acerquen al texto literario y puedan comprenderlo e interpretarlo.

El uso del dibujo y de las imágenes creadas por ellos mismos es una forma de acercarlos a la literatura, de darles armas para que empiecen a interpretar y a comprender el texto literario que están leyendo. La inclusión de las imágenes, así como del sonido es importante en esta época, pues los jóvenes han crecido junto con estos elementos en su vida cotidiana y mediante estos han aprendido a leer el mundo y a comprenderlo, por eso se les puede mostrar que con las imágenes y el sonido también es posible disfrutar de la lectura y además desarrollar otras habilidades como la oral.

Cuando se comprenda que lo importante es que el estudiante desarrolle su habilidad lectora y llegue a tener una competencia literaria que le permita leer, comprender e interpretar un texto, quizá se cambien los textos de lectura y se piense en otros que tengan relación con la vida e interese de los jóvenes, sin descuidar la calidad literaria de estos. Pero además, los docentes necesitan buscar actividades, técnicas que hagan más agradable la lectura y que permitan a los estudiantes interpretar el texto y no sea el mismo docente o un libro de texto. Las actividades existen, solo falta que el docente las ponga en práctica y que compruebe que con ellas está dando un pequeño pasó para que los jóvenes se enamoren de la lectura y esta actividad deje de ser una misión imposible 


\section{Referencias}

Alonso, Fernando. (2007). La importancia de la literatura en la escuela y en la casa. En: Biblioteca Virtual Miguel de Cervantes. Recuperado el 25 de julio del 2007. En: http://www.cervantesvirtual.com/servlet/SirveObras/06929452179503028537857/p0000 $\underline{001 . h t m \# I \quad 0}$

Alonso, Fernando. (2007b). El lector se hace en la infancia. En: Biblioteca Virtual Miguel de Cervantes. Recuperado el 26 de julio del 2007 En: http://www.cervantesvirtual.com/servlet/SirveObras/12709417714502617987213/p0000 001.htm\#l 0

Aragonés, Mónica y otras. (2007). La prensa escrita como estrategia didáctica para una enseñanza significativa del género cuento en el nivel de sétimo año de la Educación general Básica costarricense. Trabajo Final de Graduación para obtener el título de Licenciada en la Enseñanza del Castellano y la Literatura. Universidad de Costa Rica, San José, Costa Rica.

Arias, Carol y otras. (2007). Literatura comparada: Un acercamiento a La Odisea y textos no literarios, para incrementar la comprensión lectora en estudiantes de $10^{\mathrm{a}}$ año. Trabajo Final de Graduación para obtener el título de Licenciada en la Enseñanza del Castellano y la Literatura. Universidad de Costa Rica, San José, Costa Rica.

Arroya, Lucelly. (1995). La lectura como experiencia de aprendizaje en la práctica educativa. Revista de la Universidad de Caldas. Colombia. Julio-diciembre

Barhes, Roland. (1981). EI placer del texto. México: Siglo XXI

Brenes y otras. (2003). Lineamientos metodológicos para el análisis literario mediante talleres en el nivel de noveno año del Tercer Ciclo de la educación General Básica. Trabajo de graduación para alcanzar la Licenciatura en la Enseñanza del Castellano y la Literatura. Universidad de Costa Rica, San José, Costa Rica.

Borges, Jorge Luis. (1998). La poesía. En: Siete Noches. México: Fondo de Cultura Económica.

Chen Teseng, Hsin-Ju (Cristina) y Muñoz, Cinthya. (2006). El juego escénico como medio para el acercamiento al La Vorágine de José Eustacio Rivera. Trabajo final de investigación para obtener el título de Licenciadas en la Enseñanza del Castellano y la Literatura. Universidad de Costa Rica, San José, Costa Rica.

Gallardo, Isabel. (2006). ¿Por qué no leen los estudiantes en la educación secundaria? En: Educación: Revista de la Universidad de Costa Rica, 30 (2), Universidad de Costa Rica

Guevara Leandro, Marcelo. (2008, 14 de junio). Sobre las lecturas obligatorias. En: Periódico La Nación. San José, Costa Rica.

Kernan, Alvin. (1994). ¿El adiós a la lectura?. Revista Facetas №2 
Lomas, Carlos. (1999). Cómo enseñar a hacer cosas con las palabras. Volumen II. Barcelona: Paidós.

Martín Barbero, Jesús (1993). Nuevos modos de leer. En: Revista de Crítica Cultural (7), 19-23.

Martín Barbero, Jesús. (2002). Jóvenes: comunicación e identidad. En: Pensar Iberoamericana, Revista de Cultura. Número 0. Recuperada el 12 de abril 2006 de http://www.campus-oei.org/cultura/barbero.htm.

Méndez, Silvia. (2000). La mediación docente en la comprensión de lectura de textos literarios. Educación: Revista de la Universidad de Costa Rica, 24 (1). Universidad de Costa Rica.

Méndez Anchía, Silvia. (2007, 30 de abril). Rapunzel o la necesidad de librarse: lectura con adolescentes. Actualidades Educativas en Educación, Revista Electrónica 7 (1) enero-abril. ISSN1409-4703.

Méndez, Yorleny. (2005). La lectura crítica de "la Compuerta número 12" de Baldomero Lillo. Trabajo Final para optar por el grado de Licenciada en la Enseñanza del Castellano y la Literatura. Universidad de Costa Rica, San José, Costa Rica.

Ministerio de Educación Pública - MEP, Costa Rica. (2005). Plan de estudio de Español. San José: MEP.

Ostria, Mauricio. (2000). Enseñanza de la literatura en los tiempos que corren. En: Revista de la Facultad de Filosofía y Humanidades, Universidad de Chile. ISSN 0717-2869. Índice $\mathrm{N}^{\circ}$ 14, otoño. Recuperado el 24 julio del 2007 En: http://www.uchile.cl/facultades/filosofia/publicaciones/cyber/cyber14/tx26mostria.html

Penac, Daniel. (1992). Como una novela. Barcelona: Grupo Editorial Norma.

Prado Aragonés, Josefina. (2000). Didáctica de la lengua y la literatura para educar en el siglo XXI. Madrid: Editorial La Muralla

Picado, José Miguel y Palacios, Víctor. (2005). Taller artístico para la lectura de El ingenioso Hidalgo don Quijote de la Mancha. Trabajo Final de Graduación, Universidad de Costa Rica, San José, Costa Rica.

Ramírez, Catalina. (2007). Estrategias metodológicas utilizadas por docentes de sétimo año en la enseñanza del análisis literario en el Liceo de Heredia. Trabajo final de investigación para obtener el título de Licenciadas en la Enseñanza del Castellano y la Literatura. Universidad de Costa Rica, San José, Costa Rica.

Ramírez, Catalina. (2006). Estrategias metodológicas usadas por docentes de sétimo año en la enseñanza del análisis de textos literarios. Revista de Filología, Lingüística y Literatura, XXXII (2). Universidad de Costa Rica. 